Article

\title{
Current and Future Friends of the Earth: Assessing Cross-National Theories of Environmental Attitudes
}

\section{Karen Stenner ${ }^{1, *}$ and Zim Nwokora ${ }^{2}$}

1 Behavioural Economics Team, Behavioural \& Social Sciences Group, Adaptive Social \& Economic Systems Program, CSIRO (Commonwealth Scientific and Industrial Research Organisation), Dutton Park, Queensland 4102, Australia

2 Law School, University of Melbourne, Carlton, Victoria 3053, Australia; E-Mail: zim.nwokora@unimelb.edu.au

* Author to whom correspondence should be addressed; E-Mail: Karen.Stenner@csiro.au; Tel.: +61-7-3833-5745.

Academic Editor: Vincenzo Dovì

Received: 27 January 2015 / Accepted: 20 May 2015 / Published: 27 May 2015

\begin{abstract}
Empirical studies of public opinion on environmental protection have typically been grounded in Inglehart's post-materialism thesis, proposing that societal affluence encourages materially-sated publics to look beyond their interests and value the environment. These studies are generally conducted within, or at best across, Western, democratic, industrialized countries. Absence of truly cross-cultural research means the theory's limitations have gone undetected. This article draws on an exceptionally broad dataset - pooling cross-sectional survey data from 80 countries, each sampled at up to three different points over 15 years - to investigate environmental attitudes. We find that post-materialism provides little account of pro-environment attitudes across diverse cultures, and a far from adequate explanation even in the affluent West. We suggest that unique domestic interests, more than broad value systems, are driving emerging global trends in environmental attitudes. The environment's future champions may be the far from 'post-material' citizens of those developing nations most at risk of real material harm from climate change and environmental degradation.
\end{abstract}

Keywords: public opinion; environmentalism; postmaterialism; climate change; globalization 


\section{Introduction}

Climate change is a global 'tragedy of the commons' [1]. This means that solutions will require cooperation by developed and developing nations. An important, and perhaps necessary, condition for such cooperation is widespread concern among ordinary people about the potential effects of climate change. Given that environmental protection may be accompanied by real costs, policy action to combat climate change seems significantly more likely when political leaders face pressure from their citizens. As Scruggs and Benegal explain, 'while the earth's climate may not react to what people think about the climate, elected politicians often do' [2] (p. 515). And even non-elected political leaders must be somewhat sensitive to the sentiments of their societies in order to maintain the legitimacy of their regimes [3].

The translation of citizens' concerns into policy action is a complex process and there has been research investigating several key linkages in this process. One strand of research, and the one to which we aim to contribute, investigates the overarching sources of citizens' environmental attitudes. As we explain in detail in the next section, this research aims to identify the factors that account for variation in pro-environment attitudes across (and within) nations. Influential theories draw attention to individuals' social position - as determined by class, income and education — and individuals' values, namely the issues and concerns they choose to prioritize. While there are connections between these two approaches, they are usually treated as distinct perspectives on how individuals form their environmental attitudes. The first approach emphasizes the 'structural' determinants of attitudes while the second stresses that individuals, independent of their social background, can choose which values to prioritize.

There are a number of other research agendas likewise relevant for understanding the connection between pro-environment attitudes and policy action on climate change. One agenda investigates the relationship between citizens' attitudes and their patterns of behavior [4,5]. Motivating this research is the observation that attitudes do not consistently predict actions. For example, older people often behave in more environmentally friendly ways than younger people despite having weaker pro-environmental sentiments [6] (p. 770). Furthermore, there are numerous studies that examine how citizens' environmental attitudes become institutionalized in environmental movements [7-9]. These studies show that different political opportunity structures provide environmental groups with greater or lesser obstacles in their attempts to consolidate, grow, and influence policy-makers. Finally, there are studies that examine variation in the success of environmental movements, seeking to identify which circumstances enable them to secure a foothold in mainstream politics, either through an influential Green party or the adoption of pro-environment policies by older, established parties [10,11].

In this article, we analyze the determinants of citizens' environmental attitudes drawing on a much larger and far more comprehensive dataset than has been examined to date. In particular, we focus our investigation on postmaterialism theory, developed by Inglehart [12-14], which has been a highly influential framework for understanding the sources of 'green' sentiment. It posits that environmental concern depends upon satisfaction of basic material needs. It is thought that generations socialized in material affluence will lift their sights to appreciate and preserve the environment even when there are real costs to doing so. Our dataset enables a rigorous test of this thesis, as well as other general accounts of environmental attitudes, across 80 countries surveyed on up to three occasions over 15 years.

The remainder of this paper is organized as follows. In the next section we summarize the dominant theories of environmental attitudes. We then describe the sample, variables, and models that we employ 
to test these theories. We present our findings in two subsequent sections. The first presents a broadbrush overview of trends we observe in the data. In the second we use hierarchical linear modelling to assess the merits of the general theories against our cross-national data. Their limitations lead us to argue in favour of more context-specific theories of environmental concern. We conclude by discussing how this change of perspective alters our expectations of future global environmental politics.

\section{The Determinants of Public Concern about the Environment: Existing Studies}

Existing studies of environmental attitudes are rooted in two theoretical schools [15]. The 'social-structural' view presents pro-environment opinions as characteristic of certain groups defined by age, class, education, income and other cleavages. The main alternatives to 'social bases' explanations are theories highlighting 'value systems'. A consistent research finding is that pro-environment views are negatively associated with youth and positively associated with education and residence in urban areas. However, in general, most studies confirm the greater importance of values compared to social-structural factors. Thus, in their review of the scholarship, Oreg and Katz-Gerro conclude that 'social-psychological constructs such as values, attitudes, and beliefs have been more successful in predicting pro-environmental behaviours' than structural theories [15] (p. 463).

Since the 1970s, Inglehart's postmaterialism thesis has been the most prominent theoretical framework for understanding the sources of 'green' sentiment [6,16,17]. It posits that the relative abundance of material (i.e., economic and physical) security in advanced industrial countries has led to postmaterialist priorities (including environmental concern) among generations that came of age during periods of material security. The theory derives from Maslow's argument that human needs can be represented as a hierarchy. Concern for the environment is a high-level need that is generally only reached by individuals (and by implication, societies) once they have satisfied their lower-level needs for physical and economic security. Thus, it is thought that generations socialized in material affluence tend to lift their sights to appreciate and preserve the environment even when there are real costs to doing so. Because postmaterialism relies on gradual opinion change resulting from different socialization contexts the thesis differs from the simpler affluence hypothesis, which posits that environmentalism is a 'normal' good directly (and positively) related to income [18,19].

The theory was tested on Western citizens during a period of economic expansion when the most serious environmental policy problems were deferred for later resolution [20]. Additionally, postmaterialism was measured with valence questions that allowed people simply to express their general values rather than their willingness to protect the environment when faced with real trade-offs [21]. Despite these limitations postmaterialism quickly gained pre-eminence, perhaps because it predicted an increasingly wealthy world becoming more supportive of environmentalism, a much rosier future than other projections of global environmental politics.

The past two decades, however, have seen sustained challenges to the theory of postmaterialism on both methodological and practical grounds. Methodologically, critics claim Inglehart's postmaterialism measure does not capture the properties of the concept [22,23], with some arguing that postmaterialism is a proxy for education and affluence [24], or even that the materialism-postmaterialism dimension is non-existent $[25,26]$. At a practical level, the ineluctable rise of Western postmaterialists looks far from certain. Western economies stagnated just as the costs of environmental concern began to bite. And some 
research suggests that, in cases such as the United States, support for environmental action stagnated and perhaps even declined during the period of sustained economic growth in the late 1990s and early 2000s [27]. Globally, the current struggle to reach a workable agreement on greenhouse gas emissions reveals 'generally increasing antagonism between North and South' [28] (p. 137). In the North, even pro-environment voters are often 'strongly resistant to the reality of higher taxes or energy prices' [21] (p. 15).

Moreover, while postmaterialism theory predicts environmental concern will be greatest in materially-sated Western populations, the frequently negative environmental experiences in developing countries provide alternative, and potentially more powerful, stimuli for concern [29]. Environmentalism in developing countries appears often to be driven by local practicalities, and only weakly related to social structures or values. For example, pro-environment attitudes have been influenced by rising sea levels in Bangladesh [30]; soil degradation in China [31]; destruction of communal lands in Nigeria [32]; and health and safety concerns in South Korea [33]. Inglehart has responded by presenting postmaterialism as a partial theory applying only to rich countries, while environmentalism in poor countries is explainable by reference to 'objective problems' [34].

These challenges suggest limits to postmaterialism as a universal theory of environmental sentiment, but the attack is a scattered one. First, the methodological critiques tend to focus not on environmental issues but on testing the validity of the postmaterialism measure. Environmentalism is peripheral to this, with even the twelve-item index of postmaterialism including only one question on the environment [26] (p. 938). Second, comparative studies have focused disproportionately on developed nations [16,18,35-38]. Some research has used the International Social Survey Programme [19,39], but even the latest ISSP data (from the year 2000) extends to only 26 countries, most of which are Western. A handful of recent studies use the more expansive World Values Survey, but without drawing on more recent waves of data $[16,40,41]$ which, notably, have deliberately expanded coverage of non-Western, developing countries. Our investigation has even broader scope than the approximately 60 countries examined in the most comprehensive of these studies to date [16]. Third, there has been no alternative theoretical framework developed to explain public opinion on the environment. It has proved easier to dismantle the postmaterialism thesis than to replace it.

Our paper addresses these three gaps. First, we focus directly on the utility of postmaterialism as a predictor of environmental attitudes. Second, we provide a more rigorous test of postmaterialism, as well as other values and social-structural theories, by drawing on pooled survey data collected from a broad cross-section of countries (covering all major regions) over 15 critical years in global environmental politics. And third, we ultimately argue that any adequate explanation of environmental attitudes must consider - in addition to values and social-structural variables - the confluence of local problems, issue salience, and calculations of domestic interest.

Both the values and social-structural explanations are cast as general, cross-national theories and can therefore be tested using large-n statistical techniques. To do so, we draw on a pooled cross-sectional dataset including nearly 150,000 survey respondents - drawn from 80 countries whose populations were randomly sampled on up to three occasions over a 15 year period - substantially exceeding the range of existing large-n studies. Observing, by these means, any evident cross-cultural differences or over-time changes in environmental attitudes, our investigation is able to offer insights into recent patterns and possible future trends. 
We acknowledge at the outset that our empirical design is not without limitations. The 'objective problems' thesis cannot be directly tested here in the absence of data suitable for gauging the relationship between local environmental events and the dynamics of public opinion. In addition, we must emphasise that the dataset we analyze contains greater cross-national than longitudinal variation: for no country do we have more than three independent waves of survey data drawn within the 15-year period, and there is no panel of continuing respondents embedded in any of these surveys. Even so, our approach still offers the most systematic and comprehensive test to date of the leverage offered by postmaterialism (and other general theories) in accounting for environmental attitudes. The obvious alternative, a meta-analysis of existing studies, would immediately confront the problem that past empirical work focuses disproportionately on Western countries. In any case, we would certainly argue that a large-n study of a diverse cross-national dataset - pooling jointly-designed surveys sharing a great number of relevant measures (both of critical outcomes, and key explanatory factors) - is likely to produce more reliable and readily generalizable findings about the universals (or lack thereof) in the dynamics of environmental concern.

\section{Data}

\subsection{Sample and Sub-Samples}

We use data from the cumulative World Values Survey (1981-2008) (WVS) to test cross-national theories of environmental attitudes. The WVS is a 'worldwide investigation of socio-cultural and political change' [42] (p. 528). The first wave of surveys (1981) spanned 22 countries, and country coverage has been expanded significantly in the waves that have followed. At the time of this analysis, the WVS database consisted of 261 large-scale random sample surveys drawn from 99 countries across nearly three decades, incorporating 355,298 respondents. Norris observes that recent WVS data captures the attitudes of approximately 88 per cent of the world's population 'covering all six inhabited continents' [42] (p. 528). When the data were distilled to include only those surveys with two critical measures of support for environmental protection, plus all major explanatory variables (discussed below), our remaining total was 135 samples drawn from 80 countries, at up to three time points over 15 years (1994-2008), and ultimately incorporating 149,559 respondents (see Supplementary Materials, Table S1 for details). Some 'countries' are more accurately described as 'societies' as they are not uncontested, fully sovereign states: East and West Germany (WVS drew separate samples even after reunification); Hong Kong ('special administrative region' of People's Republic of China); Taiwan (sovereignty disputed by PRC); Puerto Rico (unincorporated US territory); Bosnia Federation and Republika Srpska (two entities comprising sovereign country of Bosnia and Herzegovina). However, given our focus on the values of distinct societies, there is a strong case for treating such entities as separate analytic units. Recent research using WVS data generally follows this approach [16].

Despite this trimming of the data, the sample's coverage greatly exceeds previous analyses based on WVS data (including Inglehart's). Because of the sample's breadth we are able to investigate environmental attitudes in six sub-samples (see Table S1): Western and non-Western countries (according to Huntington [43]); democracies and autocracies (following Pemstein et al. [44]); and developed and developing economies (using a median split of countries ranked by their log GDP per 
capita at the time of the WVS survey, with GDP data from Heston et al. [45]). Notice that these sub-samples overlap, so (for example) there are some non-Western / high-GDP countries (e.g., Japan, Argentina, Croatia) and some democratic nations that are neither Western nor high-GDP (e.g., India, Brazil, Turkey).

\subsection{Dependent Variable: Support for Environmental Protection}

The WVS over the years has measured a wide array of environment-related variables. But given that our key objective was detection (or refutation) of any universal influences on environmentalism across diverse cultures, we focused in on and restricted our analysis to just two relevant items, these being asked of enough WVS samples to allow for broad cross-national comparisons. Equally critical, these two items both tap willingness to bear economic costs to protect the environment, and reflect real and concrete choices. In our view, they present respondents with a more meaningful test of environmental concern than valence questions [27,37] and items requiring them simply to express their values in the abstract. In the end, these were the only two environmental questions on the cumulative WVS that fully satisfied both of these criteria (common question, presenting a real and explicit trade-off). The first question (b002) asks whether respondents agree with an 'increase in taxes if used to prevent environmental pollution', on a four-point scale ranging from 'strongly disagree' to 'strongly agree'. The second question (b008) has respondents choose between 'protecting the environment' and 'economic growth and creating jobs'. Here we arranged responses on an ordinal scale, with 'other answer' a neutral response between the two proffered options. Our overall measure of environmentalism (mean $=0.56$, $\mathrm{sd}=0.30$, range $=0-1$ across 11 points) averaged these two items, after first rescoring each to range from 0 to 1 . Note that subsequent extensive testing of the robustness of our results to alternative constructions of the dependent variable confirmed that our central findings and the conclusions drawn from them do not alter significantly if we substitute one or the other of these environmental variables for the overall measure formed by combining the two.

At this point we should note that, here and throughout, our general practice is to re-score all variables (and any measures constructed from them) that have no 'natural metric' to range (in practice) from 0 to 1 , which greatly simplifies the comparison and interpretation of estimated effects (coefficients). Variables that do have their own natural metric (in this case: age, time, and average GDP per capita in childhood) are of course left in those original units, with results interpreted accordingly.

\subsection{Independent Variable: Values and Social-Structural Factors}

\subsubsection{Values}

Foremost among potential explanatory variables is, of course, postmaterialism. Here we rely on Inglehart's 12-item index of postmaterialism furnished by the WVS [14] (pp. 415-416). This index is formed from three separate batteries where respondents indicate their first and second preferences from among four values (two postmaterialist and two materialist options). The postmaterialist values are: 'giving people more say in how things are done', 'making our cities and countryside more beautiful', 'giving people more say in government decisions', 'protecting free speech', 'progressing toward a less impersonal and more humane society', and 'a society where ideas count more than money'. 
The materialist stances are: 'maintaining high economic growth', 'ensuring strong defense forces', 'maintaining order', 'fighting rising prices', 'a stable economy', and 'fighting crime'. We rescored the index to range from 0 to 1 .

We also included a standard measure of 'left-right' self-placement [46,47], where respondents placed their own 'views' in 'political matters' on a ten-point scale (rescored to range from 0 to 1), labelled 'left' and 'right' at either end. While the meaning of these labels varies between countries, pro-environment stances generally form part of the bundle of 'left-wing' attitudes in most countries covered by the WVS.

We also included a measure of authoritarianism [48-51]: an individual's preference for obedience and conformity over freedom and difference. This value dimension cuts across the traditional 'left/right' divide [47]. We measured authoritarianism through child-rearing values [49] with respondents choosing from a list of 'qualities that children can be encouraged to learn at home' those they 'consider to be especially important'. The choice of 'obedience' reflects authoritarianism, and 'independence' and 'imagination' its inverse. We also incorporated a separate item where respondents indicated whether it would be 'a good thing' if there was 'greater respect for authority' in the future. These four items were reversed as appropriate and equally weighted in the overall measure (rescored to range from 0 to 1). We expect that authoritarians, inclined to obedience and conformity, are likely to privilege national economic strength over protection of vulnerable ecosystems.

\subsubsection{Social-Structural Factors}

To test the thesis that being socialized in a climate of material security promotes environmentalism we included a variable directly measuring the national economic prosperity experienced in respondents' youth, specifically their country's log GDP per capita averaged across their 18 years of childhood (henceforth 'affluent socialization'). It is important to bear in mind that this variable, like all others in the analysis, remains an individual-level measure, although it is informed by aggregate country-level data. Respondents surveyed even at the same time in the same country will accrue a very wide array of societal affluence scores, since (for example) someone who has just come of age will have experienced in their childhood a different economic and cultural climate than that prevailing across the 18 years during which (say) some elderly counterpart being interviewed contemporaneously was socialized. A survey of around 1000 respondents will typically yield about 60 different 'affluent socialization' scores, just in that one country in a particular year, so the range is considerable. The levels will then vary enormously_ with the ranges perhaps not even overlapping — across different societies.

In sum, this critical measure for our analysis takes the most widely accepted indicator of national economic prosperity, observes its level for each of the 18 years spanning a particular respondent's upbringing, and then averages across those 18 scores to reflect the societal affluence that that particular respondent experienced in their childhood. The measure reflects societal wealth (not household wealth) at the time one was growing up, because it is societal affluence (rather than the prosperity of one's own parents/household) that is purportedly critical for nurturing a postmaterial perspective.

We did test two other measures of material affluence that reflected the individual's current household prosperity, rather than that of the society in which they were raised. We included, first, a measure of family income decile within nation (rescored from 0-1); and, second, satisfaction with one's household financial situation (10 point scale, rescored $0-1)$. We then extended beyond material security to measure 
how satisfied respondents were with their 'life as a whole these days' (10 point scale, rescored 0-1), and whether 'taking all things together' they were 'very happy, quite happy, not very happy, or not at all happy' (4 point scale rescored $0-1$ ).

We also tested the impact of several variables relating to social location. We used an 8-point variable reflecting highest level of education attained, from incomplete primary schooling (scored 0 ) to postgraduate qualification (scored 1). Age was simply measured in decades (i.e., 65 years was scored 6.5), but the concept of generation presented difficulties given that the purportedly critical eras of socialization varied across countries. In the end, we covered the main cultural fault line common to many countries via a dummy variable scored ' 1 ' if the respondent was born since the 1980 s ('Gen $Y$ ' in the West, and variously named elsewhere), and ' 0 ' otherwise.

\subsection{Control Variables: Trust and Institutional Confidence; Sex, Religion, and Ethnicity}

The perceived effectiveness of interventions may well rest on one's confidence in fellow citizens and social institutions. After all, environmental protection is a collective action problem and trust is often necessary for the solution of such problems [52,53]. Thus, an individuals' willingness to sacrifice economic growth for leap-of-faith efforts at environmental protection might be tempered by low inter-personal trust or lack of institutional confidence. Neither has been routinely included in prior research. We controlled for inter-personal trust using the item: 'generally speaking, would you say that most people can be trusted or that you need to be very careful in dealing with people?' (dummy variable 1/0). We gauged institutional confidence by ascertaining whether respondents had 'a great deal of confidence, quite a lot of confidence, not much confidence, or none at all' in each of the following: the armed forces, press, labour unions, police, parliament, civil services, television, government, political parties, justice system, and major companies (averaged and re-scored to range 0 to 1 overall; $\alpha=0.87$ ).

Finally, we also controlled for sex (with men generally considered less sympathetic to environmental causes), as well as religious denomination and ethnicity. The latter were controlled in all analyses via an extensive set of dummy variables: 14 categories for denomination and 18 categories for ethnicity (full results are available from authors upon request).

\section{Broad Patterns and Trends in Support for Environmental Protection}

Before moving to the multivariate analyses, we first consider whether any patterns can be discerned by looking in broad overview at the earliest and latest data available for each of the 80 countries. Table 1 ranks these countries based on: (1) citizens' average scores (according to the latest WVS survey) on environmentalism, postmaterialism, and 'affluent socialization'; as well as (2) national scores (at the time of the latest WVS survey) for level of democracy and log GDP per capita.

Focusing first on countries with multiple waves of data, the immediate surprise is that there seems to have been no general rise in support for environmental protection, and this over a decade (1996-2006 is the typical span) ranging from adoption of the Kyoto Protocol through to its ratification by most signatories. We see only a waxing and waning of support far too idiosyncratic and country-specific to suggest a global, regional, or cultural shift in sentiment. If anything, there has been a general downturn in willingness to bear economic costs to protect the environment. Of the 41 countries with environmentalism measured on at least two occasions, 25 experienced a decline in public support 
between their earliest and latest WVS waves, averaging 7 percentage points (that is, -0.07 on the measure's $0-1$ scale). Moreover, the downward trend is actually most marked in some of the more affluent countries, including South Korea $(-0.25)$, Taiwan $(-0.15)$, West $(-0.16)$ and East Germany $(-0.13)$.

Table 1. Countries ranked by environmentalism, postmaterialism and affluence.

\begin{tabular}{|c|c|c|c|c|c|c|}
\hline Country (Years) & $\begin{array}{l}\text { Environ. } \\
\text { (earliest) }\end{array}$ & $\begin{array}{l}\text { Environ. } \\
\text { (latest) }\end{array}$ & $\begin{array}{l}\text { Environ. } \\
\text { Rank }\end{array}$ & $\begin{array}{l}\text { Postmaterial. } \\
\text { Rank }\end{array}$ & $\begin{array}{l}\text { Affluent } \\
\text { Socializ. Rank }\end{array}$ & $\begin{array}{l}\operatorname{logGDP} / \text { cap. } \\
\text { Rank }\end{array}$ \\
\hline El Salvador (1999) & . & 0.78 & 1 & 23 & 48 & 52 \\
\hline Dominican Rep. (1996) & . & 0.75 & 2 & 9 & 51 & 50 \\
\hline Andorra (2005) & . & 0.71 & 3 & 1 & 14 & 22 \\
\hline Vietnam (2001-2006) & 0.68 & 0.71 & 4 & 46 & 70 & 64 \\
\hline Norway (1996-2007) & 0.64 & 0.69 & 5 & 4 & 4 & 1 \\
\hline Puerto Rico(1995-2001) & 0.72 & 0.68 & 6 & 8 & 24 & 17 \\
\hline Tanzania (2001) & . & 0.66 & 7 & 41 & 76 & 78 \\
\hline China (1995-2007) & 0.67 & 0.66 & 8 & 77 & 69 & 45 \\
\hline Switzerland (1996-2007) & 0.49 & 0.65 & 9 & 2 & 1 & 3 \\
\hline Canada (2000-2006) & 0.61 & 0.65 & 10 & 7 & 7 & 5 \\
\hline Burkina Faso (2007) & . & 0.63 & 11 & 45 & 75 & 76 \\
\hline Mexico (1996-2005) & 0.57 & 0.63 & 12 & 16 & 28 & 27 \\
\hline Croatia (1996) & . & 0.63 & 13 & 17 & 19 & 35 \\
\hline Sweden (1996-2006) & 0.70 & 0.62 & 14 & 3 & 6 & 6 \\
\hline Peru (1996-2006) & 0.54 & 0.62 & 15 & 20 & 40 & 48 \\
\hline Cyprus (2006) & . & 0.62 & 16 & 35 & 27 & 21 \\
\hline Mali (2007) & . & 0.62 & 17 & 55 & 78 & 74 \\
\hline Philippines (1996-2001) & 0.61 & 0.62 & 18 & 36 & 66 & 66 \\
\hline India (1995-2006) & 0.45 & 0.62 & 19 & 40 & 71 & 63 \\
\hline Australia(1995-2005) & 0.62 & 0.61 & 20 & 13 & 8 & 4 \\
\hline Belarus (1996) & . & 0.61 & 21 & 58 & 36 & 58 \\
\hline Argentina (1995-2006) & 0.49 & 0.60 & 22 & 21 & 26 & 30 \\
\hline Bangladesh (1996-2002) & 0.60 & 0.60 & 23 & 49 & 73 & 72 \\
\hline Turkey (1996-2007) & 0.62 & 0.60 & 24 & 31 & 35 & 31 \\
\hline Russia (1995) & . & 0.60 & 25 & 75 & 46 & 38 \\
\hline Chile (1996-2006) & 0.59 & 0.60 & 26 & 15 & 37 & 28 \\
\hline Finland (1996-2005) & 0.48 & 0.59 & 27 & 12 & 10 & 11 \\
\hline Rwanda (2007) & . & 0.59 & 28 & 24 & 74 & 75 \\
\hline Guatemala (2004) & . & 0.58 & 29 & 44 & 45 & 51 \\
\hline Italy $(2005)$ & . & 0.58 & 30 & 10 & 11 & 13 \\
\hline New Zealand (1998-2004) & 0.53 & 0.58 & 31 & 19 & 9 & 16 \\
\hline Czech Republic (1998) & . & 0.58 & 32 & 47 & 13 & 23 \\
\hline Venezuela (1996) & . & 0.58 & 33 & 28 & 22 & 36 \\
\hline Brazil (1997-2006) & 0.60 & 0.58 & 34 & 25 & 39 & 43 \\
\hline Moldova(1996-2006) & 0.61 & 0.57 & 35 & 52 & 54 & 65 \\
\hline Trinidad \& Tobago (2006) & . & 0.56 & 36 & 42 & 23 & 18 \\
\hline Ghana (2007) & . & 0.56 & 37 & 57 & 72 & 71 \\
\hline Bosnia Fed. (1998-2001) & 0.51 & 0.56 & 38 & 66 & 60 & 53 \\
\hline
\end{tabular}


Table 1. Cont.

\begin{tabular}{|c|c|c|c|c|c|c|}
\hline Country (Years) & $\begin{array}{l}\text { Environ. } \\
\text { (earliest) }\end{array}$ & $\begin{array}{l}\text { Environ. } \\
\text { (latest) }\end{array}$ & $\begin{array}{l}\text { Environ. } \\
\text { Rank }\end{array}$ & $\begin{array}{l}\text { Postmaterial. } \\
\text { Rank }\end{array}$ & $\begin{array}{l}\text { Affluent } \\
\text { Socializ. Rank }\end{array}$ & $\begin{array}{l}\text { logGDP/cap. } \\
\text { Rank }\end{array}$ \\
\hline Serbia (1996-2006) & 0.58 & 0.56 & 39 & 64 & 47 & 42 \\
\hline $\operatorname{Iran}(2007)$ & . & 0.56 & 40 & 43 & 30 & 32 \\
\hline Spain (1995-2007) & 0.60 & 0.56 & 41 & 18 & 15 & 14 \\
\hline Azerbaijan (1997) & . & 0.56 & 42 & 76 & 53 & 67 \\
\hline Japan (1995-2005) & 0.57 & 0.56 & 43 & 22 & 18 & 12 \\
\hline Indonesia (2006) & . & 0.55 & 44 & 56 & 65 & 61 \\
\hline Thailand (2007) & . & 0.55 & 45 & 30 & 61 & 41 \\
\hline Macedonia(1998-2001) & 0.57 & 0.54 & 46 & 74 & 55 & 49 \\
\hline Slovenia (1995-2005) & 0.54 & 0.54 & 47 & 14 & 17 & 19 \\
\hline Albania (1998-2002) & 0.50 & 0.54 & 48 & 80 & 56 & 60 \\
\hline Taiwan (1994-2006) & 0.69 & 0.54 & 49 & 78 & 41 & 15 \\
\hline Rep. Srpska(1998-2001) & 0.56 & 0.54 & 50 & 73 & 59 & 54 \\
\hline Malaysia (2006) & . & 0.53 & 51 & 27 & 43 & 29 \\
\hline Georgia (1996-2009) & 0.63 & 0.53 & 52 & 72 & 58 & 55 \\
\hline Latvia (1996) & . & 0.53 & 53 & 48 & 25 & 47 \\
\hline Slovakia (1998) & . & 0.52 & 54 & 65 & 20 & 25 \\
\hline Kyrgyzstan (2003) & . & 0.52 & 55 & 54 & 52 & 69 \\
\hline Estonia (1996) & . & 0.52 & 56 & 37 & 29 & 40 \\
\hline Morocco (2007) & . & 0.52 & 57 & 60 & 63 & 62 \\
\hline USA (1995-2006) & 0.55 & 0.52 & 58 & 32 & 2 & 2 \\
\hline Ukraine (1996-2006) & 0.57 & 0.51 & 59 & 50 & 33 & 46 \\
\hline Jordan (2007) & . & 0.50 & 60 & 62 & 50 & 59 \\
\hline Montenegro(1996-2001) & 0.58 & 0.50 & 61 & 71 & 57 & 56 \\
\hline Bulgaria (1997-2006) & 0.54 & 0.50 & 62 & 69 & 44 & 33 \\
\hline Armenia (1997) & . & 0.50 & 63 & 67 & 62 & 68 \\
\hline Uruguay (1996-2006) & 0.64 & 0.48 & 64 & 11 & 34 & 34 \\
\hline Nigeria (1995) & . & 0.47 & 65 & 39 & 67 & 73 \\
\hline Hong Kong (2005) & . & 0.47 & 66 & 61 & 21 & 8 \\
\hline South Korea (1996-2005) & 0.71 & 0.46 & 67 & 38 & 42 & 20 \\
\hline Romania (1998-2005) & 0.60 & 0.46 & 68 & 63 & 49 & 37 \\
\hline Poland (1997-2005) & 0.51 & 0.45 & 69 & 29 & 31 & 24 \\
\hline Lithuania (1997) & . & 0.44 & 70 & 68 & 32 & 39 \\
\hline Singapore (2002) & . & 0.43 & 71 & 34 & 12 & 7 \\
\hline Ethiopia (2007) & . & 0.43 & 72 & 26 & 79 & 79 \\
\hline Zambia (2007) & . & 0.42 & 73 & 33 & 68 & 70 \\
\hline Zimbabwe (2001) & . & 0.42 & 74 & 51 & 80 & 80 \\
\hline Uganda (2001) & . & 0.42 & 75 & 59 & 77 & 77 \\
\hline Egypt (2008) & . & 0.42 & 76 & 70 & 64 & 57 \\
\hline W. Germany (1997-2006) & 0.57 & 0.41 & 77 & 5 & 3 & 9 \\
\hline South Africa (1996-2006) & 0.38 & 0.40 & 78 & 53 & 38 & 44 \\
\hline Hungary (1998) & . & 0.39 & 79 & 79 & 16 & 26 \\
\hline E. Germany (1997-2006) & 0.47 & 0.34 & 80 & 6 & 5 & 10 \\
\hline
\end{tabular}

Sources: For attitudes WVS; for GDP Heston, Summers and Aten (2011): purchasing power parity (int'l prices). 
Considering now all 80 countries in Table 1 (including those with just one wave of data), there are clearly significant deviations from the expected pattern of environmentalism being nourished by a climate of postmaterialism and national affluence. In the top quartile of Table 1 there are conforming cases, such as Norway, Switzerland, Canada, Sweden and Australia. But there are at least as many cases that contradict the postmaterialism theory, including Vietnam, Tanzania, China, Burkina Faso, Mali, the Philippines and India. No country has witnessed a more explosive growth in environmentalism than India: a hefty 17 percentage point rise between 1995 and 2006 (from 0.45 to 0.62 on the $0-1$ scale). But it remains a country with hardly a whiff of postmaterialist sentiment and where, despite recent economic growth, the average citizen remains impoverished. These unexpected 'greenies' in Asia and Africa seem willing to bear real costs to protect the environment, without the impetus of affluence (either in childhood or at present), or any disavowal of their pressing material concerns.

At the bottom of Table 1, Egypt, Uganda, Zimbabwe, Zambia and Ethiopia all manifest the expected intersection of impoverishment, fixation on materialism, and disregard for the environment. But again, there are departures from the expected pattern with East and, especially, West Germany the most obvious deviations. Although one of the first publics to support a 'Grün' party and elect green candidates to a national legislature, Germany has experienced a precipitous decline in environmental concern, despite long experience with affluence and still high levels of postmaterialism. For instance, in the 1997 WVS, both West and East Germans displayed a willingness to 'increase taxes to prevent environmental pollution' that essentially halved over the next couple of years, and remained around that level in 2006. It seems that Germans' continuing desire for self-expression and self-actualization no longer translates consistently into concern for the environment.

Although never notably inclined toward postmaterialism, the citizens of the US and, to a lesser extent, Singapore and Hong Kong also represent publics that have experienced considerable affluence without lifting their aspirations to environmental protection. And we should emphasize, again, that while South Koreans' disregard for the environment saw them hovering around the bottom of these rankingsscoring just 0.46 on environmentalism - they plummeted to that lowly position from an almost unparalleled score of 0.71 over a decade in which their levels of postmaterialism and affluence barely shifted.

\section{Cross-National Determinants of Support for Environmental Protection}

This broad overview indicates that postmaterialism provides, at best, an incomplete account of the variance in public opinion on environmental issues. The results of our hierarchical linear modelling (see Table 2) tend to confirm this and show, further, that other values and social-structural theories are likewise weak explanations of public support for environmental protection.

These 'fixed effects' (reported in upper panel, Table 2) are unstandardized multiple regression coefficients (with standard errors in parentheses). They are derived from hierarchical linear modelling of a two-level random intercept model, with the grouping structure of the data consisting of nested groups that vary according to WVS 'national wave' (a certain nation in a particular year). We see evidence of variation in the intercepts across these WVS national waves (see 'random effects', middle panel, Table 2). Comparing the fit of the random intercept model to a standard regression model yields a likelihood ratio test ( $v s$. linear regression) of $5500(\mathrm{p}=0.000)$. One can think of this 'random intercept' HLM as equivalent to a standard regression model with an exhaustive series of dummy variables entered into the analysis, to represent each of the WVS national waves. The lesser variance explained by the standard regression 
model relative to one allowing the intercepts to vary across WVS national waves (see 'variance explained', lower panel, Table 2) shows clearly that we can greatly improve (especially outside the West) our account of environmental concern if we accommodate cross-wave/cross-national differences in baseline attitudes toward environmental protection. On its own, this tends to support our central intuition that a good deal of the variation in environmental sentiment is linked to changeable, malleable, local conditions, and not so heavily influenced by purportedly universal ideological/psychological influences and enduring socio-structural factors.

Table 2. Determinants of public support for environmental protection, across cultures.

\begin{tabular}{|c|c|c|c|c|c|c|c|}
\hline & & & & Sub-Samples & & & \\
\hline & All & West & Non-West & Higher GDP & Lower GDP & Democracies & Autocracies \\
\hline Fixed Effects & b(s.e.) & b(s.e.) & b(s.e.) & $b($ s.e. $)$ & b(s.e.) & b(s.e.) & b(s.e.) \\
\hline time (year 0-14) & $-0.0012(0.0015)$ & $0.0008(0.003)$ & $-0.0016(0.0017)$ & $-0.0022(0.0019)$ & $-0.0015(0.002)$ & $-0.0006(0.0017)$ & $-0.0013(0.0031)$ \\
\hline post-materialism & $0.12(0.003) *$ & $0.197(0.008) *$ & $0.089(0.004) *$ & $0.159(0.005) *$ & $0.071(0.005) *$ & $0.136(0.004) *$ & $0.072(0.007) *$ \\
\hline authoritarianism & $-0.021(0.003) *$ & $-0.073(0.007) *$ & $0.001(0.004)$ & $-0.039(0.005) *$ & $0.003(0.005)$ & $-0.03(0.004) *$ & $0.009(0.006)$ \\
\hline GDPpc in R's youth & $-0.0011(0.0029)$ & $-0.0107(0.0094)$ & $0.0056(0.0032)$ & $-0.0053(0.0045)$ & $0.0068(0.0044)$ & $-0.0114(0.0038) *$ & $0.0162(0.0048) *$ \\
\hline income decile & $0.013(0.003) *$ & $0.014(0.007) *$ & $0.016(0.004) *$ & $0.019(0.005) *$ & $0.005(0.005)$ & $0.014(0.004) *$ & $0.005(0.007)$ \\
\hline financial satisfaction & $0.033(0.003) *$ & $0.039(0.008) *$ & $0.035(0.004) *$ & $0.03(0.005) *$ & $0.039(0.005) *$ & $0.037(0.004) *$ & $0.028(0.007) *$ \\
\hline life satisfaction & $0.045(0.004) *$ & $0.032(0.01) *$ & $0.046(0.004) *$ & $0.047(0.006) *$ & $0.043(0.005) *$ & $0.047(0.004) *$ & $0.042(0.007) *$ \\
\hline education level & $0.071(0.003) *$ & $0.102(0.006) *$ & $0.062(0.003) *$ & $0.083(0.004) *$ & $0.058(0.004) *$ & $0.081(0.003) *$ & $0.042(0.005) *$ \\
\hline age (in decades) & $-0.0035(0.0007) *$ & $-0.0071(0.0017)^{*}$ & $-0.0017(0.0008) *$ & $-0.0041(0.0011)^{*}$ & $-0.002(0.001) *$ & $-0.0047(0.0009) *$ & $-0.0022(0.0013)$ \\
\hline "gen Y"/born 1980s+ & $-0.009(0.003) *$ & $-0.023(0.008) *$ & $-0.005(0.003)$ & $-0.015(0.004) *$ & $-0.004(0.004)$ & $-0.01(0.004) *$ & $0.000(0.005)$ \\
\hline male & $-0.005(0.001)^{*}$ & $-0.015(0.003) *$ & $-0.002(0.002)$ & $-0.012(0.002)^{*}$ & $0.002(0.002)$ & $-0.007(0.002) *$ & $0.001(0.003)$ \\
\hline confid in institutions & $0.096(0.005) *$ & $0.102(0.014) *$ & $0.093(0.005) *$ & $0.085(0.008) *$ & $0.104(0.007) *$ & $0.089(0.006) *$ & $0.104(0.009) *$ \\
\hline inter-personal trust & $0.032(0.002) *$ & $0.039(0.004) *$ & $0.026(0.002) *$ & $0.035(0.002) *$ & $0.024(0.003) *$ & $0.031(0.002) *$ & $0.03(0.004) *$ \\
\hline Cons & $0.421(0.036) *$ & $0.593(0.191) *$ & $0.298(0.04) *$ & $0.448(0.099) *$ & $0.294(0.049) *$ & $0.55(0.047) *$ & $0.192(0.06) *$ \\
\hline \multicolumn{8}{|l|}{ Random Effects } \\
\hline sd(cons) & $0.077(0.005) *$ & $0.071(0.011) *$ & $0.076(0.006) *$ & $0.069(0.006) *$ & $0.068(0.007) *$ & $0.073(0.006) *$ & $0.082(0.011) *$ \\
\hline$\underline{\text { sd(residual) }}$ & $0.286(0.000) *$ & $0.277(0.001) *$ & $0.287(00.001) *$ & $0.281(00.001) *$ & $0.289(00.001) *$ & $0.284(00.001) *$ & $0.289(0.001) *$ \\
\hline \multicolumn{8}{|l|}{ Variance Explained } \\
\hline -standard model & 0.073 & 0.14 & 0.065 & 0.083 & 0.08 & 0.082 & 0.067 \\
\hline -varying intercepts & 0.11 & 0.168 & 0.102 & 0.117 & 0.108 & 0.115 & 0.101 \\
\hline \multicolumn{8}{|l|}{ LR test vs. lin reg: } \\
\hline chibar2(01) & 5500 & 824 & 4409 & 2453 & 2165 & 3543 & 1446 \\
\hline Prob $>=$ chibar 2 & 0.000 & 0.000 & 0.000 & 0.000 & 0.000 & 0.000 & 0.000 \\
\hline \# observations & 149,559 & 28,080 & 121,479 & 71,183 & 78,376 & 106,371 & 43,188 \\
\hline \# groups & 135 & 27 & 108 & 69 & 66 & 99 & 36 \\
\hline average obs/group & 1108 & 1040 & 1125 & 1032 & 1188 & 1075 & 1200 \\
\hline
\end{tabular}

Note: Cell entries (see 'Fixed Effects', upper panel) are unstandardized multiple regression coefficients, and standard errors (* significant at $\mathrm{p}<0.05$ or better), derived from hierarchical linear modelling of two-level random intercept model, nested according to WVS 'national wave' (a certain nation in a particular year); $s d$ (cons) = between-national-waves standard deviation; $s d$ (residual)=between-individuals standard deviation; LR test vs. lin reg: $\operatorname{chibar2}(01)=$ likelihood ratio test for significant difference between the two models (random intercept vs. linear regression), which is distributed chi-square with 1 degree of freedom; Prob $\geq$ chibar2 = p-value for chi-square test. Source: World Values Survey (1994-2008). See text for elaboration, measurement and scoring of variables. 
As for those fixed effects, it is notable, first, that the coefficients attached to the passage of time are insignificant across samples and, with one exception, negative, suggesting that, if anything, environmentalism has marginally decreased over time. The slight exception to this downward drift was in the core of the West, where there may have been a trivial (and statistically insignificant) rise in willingness to bear the economic costs of environmental protection. Multiplying the unstandardized coefficient $b$ by the full range of time $-0.0008 \times 14$ years - yields just 0.0112 : a rise that amounts to a mere one percentage point boost (across the $0-1$ scale of the dependent variable, environmentalism) over the decade and a half following the Kyoto Protocol.

\subsection{Postmaterialism}

The multivariate model explains about 14 percent of the variance in Western attitudes toward environmental protection, but less than $7 \%$ outside the West: less than half the explanatory power. In short, the cross-national theories work better in the West but, even there, they leave much unexplained. Consistent with Inglehart's research, postmaterialism is the most important source of environmental sentiment in Western nations. Even so, it accounts for less than 3 per cent of the variance in attitudes toward environmental protection. As for its magnitude of impact, moving across the full range of the postmaterialism scale - from hardened materialists to ardent devotees of self-actualization — shifts us only a fifth of the way across the environmentalism measure, increasing support for environmental protection by just 20 percentage points. Specifically, the unstandardized coefficient in the Western subset $(b=0.197$ ) indicates that a one-unit increase in postmaterialism (i.e., the full range of the $0-1$ measure) is expected to increase environmentalism by about 0.20 on its $0-1$ scale, holding all else constant. Moreover, the influence and impact of postmaterialism are roughly halved outside the West. Across the entire dataset (merging 135 samples), it does remain the most important explanatory variable but the overall effect is still modest. Postmaterialism apparently explains just $1 \%$ of the variance in environmentalism around the globe, and boosts support for environmental protection by just 12 percentage points.

\subsection{Other Values}

It is only in the West that environmental attitudes are at all ideologically structured. This is unsurprising given Western politicians' longer experience in marketing green issues as extensions of the traditional 'left-right' economic divide. Apart from the influence of postmaterialism, support for environmental protection across affluent Western democracies also depends on left-right self-placement and, to a lesser degree, authoritarianism. For example, Westerners who place themselves at the extreme 'right-wing' are around 17 percentage points less willing than ardent 'leftists' to tolerate taxes and restraints on economic growth to protect the environment.

\subsection{Education}

While scholars point to education as the primary means through which people are exposed to the values associated with environmental protection, our results indicate that non-Western education does not effectively transmit these values. The environmental returns to education are meager outside affluent 
Western democracies. Even there, it apparently takes a lot of education to boost green sentiment. Individuals with higher degrees are predicted to be only 8-10 percentage points more supportive of environmental protection than those not completing elementary school (an effect that drops to just 4-6 percentage points outside affluent Western democracies). Education explains just one percent of the variance in environmentalism even in the West.

\subsection{Age and Generation}

The effects of age are likewise culturally variant and surprisingly slight. Age generally proves to be a (statistically) significant dampener of enthusiasm for environmental protection. But the effects are very modest, especially outside of wealthy Western democracies, where the youngest and eldest differ in willingness to protect the environment by barely a percentage point. Even within affluent Western democracies, ageing many decades — say, maturing from 20 to 80 - tends to diminish environmentalism by four percentage points at most; the youngest are barely more enthusiastic than the eldest. Moreover, those born since the 1980s ('Gen Y') are actually a couple of percentage points less concerned for the environment than earlier generations.

\subsection{Affluent Socialization}

Finally, contrary to theoretical expectations, our results suggest that a prosperous upbringing generally has no significant impact on environmental concern later in life, and if anything, may somewhat diminish environmentalism, especially in democratic societies (as may have been the case in Germany and the USA, for example). Conversely, impoverished childhoods-perhaps upbringings marred by famine or flood, or at least precariously dependent on careful management of natural resources - may build yearning for environmental protection, at least among democratic citizens with some tangible control over their collective fates (see penultimate column of Table 2). This pattern is evidenced in the democratic countries of Asia (e.g., Philippines, India, Bangladesh) and Africa (e.g., Mali). These effects are statistically significant but very modest. Generally speaking, across democracies, an increase of two standard deviation units in childhood experience of national prosperity tends to depress environmentalism by about 2 percentage points. This finding proves robust to repeated sampling, and to substituting in varied indicators of respondents' childhood experience of national well-being (e.g., alternately deploying Log GNI per capita, or the UN Human Development Index, again averaged across the 18 years of the respondent's childhood).

Notice this stands in sharp contrast to the only other significant result concerning societal affluence in childhood (see final column, Table 2): that upbringings in impoverished non-democratic societieswhere people have little control of political outcomes (North/East Africa, for example) — do not generally provide fertile ground for nurturing environmental concern, a finding more in line with conventional theories.

\section{Toward Context-Sensitive Theories of Environmental Concern}

Our findings show the limited leverage to be gained from cross-national theories of environmental concern. We agree with Brechin's conclusion that 'environmentalism is most likely a complex social 
phenomenon, a mixture of social perceptions, local histories and environmental realities, international relationships and influences, and unique cultural and structural features of particular countries and regions' [14] (p. 807). Because of this complexity, both the levels and sources of environmentalism are likely to vary substantially both across and within nations. Accounts of environmental public opinion should, therefore, be grounded in the contextual features that impact a population's perception of the meaning, necessity, costs and benefits of environmental protection. Clearly these contextual features may take a variety of forms, and may occasionally include value systems such as postmaterialism, as well as social-structural variables. However, three factors that are wholly absent from the theories tested in this paper are likely to be important in context-sensitive accounts.

First, a population's experience of environmental events will likely impact on their attitudes toward environmental protection. The literature has shown this to be true for poor countries but it seems no less likely to be a key factor for wealthy populations. In his OPSV thesis, Inglehart still maintains that values account for environmental attitudes in rich countries, but our analyses here attest to their weak explanatory power. Inclusion of objective problems in our models would surely improve understanding of environmental sentiments in rich and poor countries alike.

Second, context-sensitive theories should be attentive to the salience of environmental issues in a particular time and place. Green sentiment is likely to be greater when environmental issues are highly salient [20]. However, salience is a variable, not a constant. While not ignoring issue salience, postmaterialism theory tends to view it in simplistic terms as a function of popular sentiments. Yet the reality is that motivated political leaders and mobilized activists, and specific events - such as a warmer-than-expected winter - can heighten issue salience, which may in turn influence public attitudes on the environment $[20,54]$.

Third, to properly account for the opinions of a particular population, theories must give due weight to the (materialist) calculations of the costs and benefits of environmental protection. Controlling pollution can be expensive and the benefits from polluting activity may be substantial. In most situations, therefore, citizens are unlikely to take an absolutist stance, choosing instead to balance the benefits of a cleaner environment against the costs of environmental protection. Countries, and constituencies within countries, may disagree on the appropriate level of environmental protection, based on their perceptions of the accompanying material costs and benefits.

By their nature, postmaterialist accounts (and others in a similar vein) - even when explicitly cross-national - tend to discount multi-factor explanations of environmental concern, in general, and material considerations, in particular. But in their absence, it is difficult to account for some of the curious empirical results from our cross-national testing.

Certainly, the United States has witnessed a decline since its 1970 s peak of environmental concern, presumably partly due to a creeping recognition of the costs of action, with the public coming to 'realize the immensity of the social and financial costs of cleaning up our air and water' [55] (p. 43). Consistent with theories of political responsiveness to citizens' opinions [56], the United States was a vanguard nation in the 1972 UN Conference on the Human Environment and in several environmental protection treaties that followed [57] (p. 336). But by the 1990s, the United States had abandoned its leadership role and had become a 'laggard and obstructionist' in the area of environmental politics [57] (p. 336). Since the 1980s, the EU nations have replaced America as leaders of the pro-environment agenda. However, we would expect the EU soon to follow the American pattern. Awareness and alarm should 
eventually be succeeded by a gradual waning of the issue, especially to the extent that pursuing the pro-environment agenda is perceived as costly, and most of the adverse consequences are borne by others (in developing countries).

Our empirical results support the notion that European countries are beginning to baulk at the costs of curbing their pollution. Initially these costs were masked by the global agreement to make 1990s emissions (rather than projected 'business as usual' emissions) the baseline for assessing country reductions post-Kyoto. This agreement made Europeans (and especially Germans) appear better 'green citizens' than they really were. Closing down East German industries created a post-reunification emissions reduction 'windfall' that enabled Germany to easily meet its obligations while leaving room for other EU states' emissions to grow, sometimes significantly [21,58]. As this dividend has now been consumed, further reductions will require economic sacrifices that are likely to be increasingly unpalatable to European mass publics. Our data show, for instance, that from 1997 to 2006, both East and West Germans plummeted roughly 15 percentage points in professed willingness to bear real economic costs to protect the environment.

Our results also show that environmental concern is high in countries like Vietnam, China, the Philippines and India, which have few of the purported preconditions for postmaterialist sentiments but suffer the adverse consequences of serious environmental events. Conversely, in Hong Kong and Singapore, the seemingly favourable preconditions for postmaterialism have yielded no abundance of postmaterialists or environmentalists. Both sets of observations contradict Inglehart's thesis, with environmental concern seeming to depend more on a palpable sense there is a problem to be solved. This condition is realized where there are numerous victims of environmental events but absent when a population is relatively insulated from substantial environmental costs.

\section{Conclusion: Current and Future Friends of the Earth}

Overall, our findings paint a less rosy picture of global mass support for environmental protection than that anticipated by popular cross-national theories. The postmaterialism thesis, in particular, envisages a world growing increasingly wealthy and industrialized (implicitly: modernized and westernized), which evolves predictably toward greater enthusiasm for environmental protection. Our analysis has exposed the weak foundations underlying this optimistic prediction.

It is only in affluent countries, and the Western world in particular, that attitudes toward environmental protection are driven by values such as postmaterialism, left-right ideology or authoritarianism. Even in the West, while environmental attitudes are better explained by values than by any other cross-national factor, they are not well explained by values. Without extensive longitudinal data we are unable to say whether Western attitudes are less structured by values than they were but certainly they are not heavily structured by values now. And outside of the affluent West, these attitudes are hardly structured at all. Little of the variance in public opinion outside the West can be explained using any of the universal, cross-national theories. The general pattern of results is consistent with mass opinion being determined largely by factors specific to a particular population, namely, the occurrence of environmental events, the salience of environmental issues on the domestic political agenda, and calculation of the costs and benefits accruing from environmental protection. 
In contrast to the dominant cross-national accounts, what would a more context-specific explanation of variation in environmental concern imply for the future of global environmental politics? We think it suggests three major amendments to the 'Inglehart story'.

First, our confirmation of the poor explanatory power of cross-national accounts suggests that the future of environmental politics will be highly unpredictable. There are no psychological or socio-structural factors that consistently boost or diminish environmental sentiment across nations, regions and cultures. Pro-environment attitudes have diverse origins, and may therefore have varying future trajectories dependent on local contexts. Since experience, salience, and interests are not broadly shared, future environmental politics will be more uncertain and the bases of international cooperation unstable.

Second, the West may be the wrong place to look for leadership of the pro-environment agenda. Even in Western nations with a large proportion of postmaterialists, that orientation is not a strong predictor of pro-environment attitudes. Other distinctive features of Western nations, notably wealth and education, do not appreciably promote environmentalism. Of course, the environmental issue is sufficiently grave that it will not be soon or easily ignored, but its salience will decline and support for costly measures will dissipate. A useful boon to the movement in the West was provided by the Stern Review (2006), which determined that the costs of inaction would greatly exceed the costs of action to protect the environment. This logic may compel Western governments to do more to solve the world's emissions problems. But the actions that result from such calculations should not be interpreted as postmaterialist in origin. Rather, they are a consequence of straightforward materialist assessment of domestic costs and benefits.

The third implication is that calculations of costs and benefits may induce some major developing countries, especially China and India, to take the lead in the area of environmental protection. And again, these countries are likely to be motivated more by interests than values. In China, for instance, environmental protection efforts are increasingly driven by concern for public health and/or economic benefit. For example, policies intended to improve sanitation, reduce respiratory illness, ease congestion, or attract tourism can also mitigate emissions and increase interest in environmental protection $[59,60]$. Clearly, it is possible to care for the environment without caring about the environment, and around the globe environmental action may increasingly be driven by such divergent forces.

Finally, we can also imagine a new wave of environmentalism springing from anti-materialism instead of post-materialism: a reaction against industrialization, and in favour of a simpler, safer, 'traditional' life. Certainly this is conceivable for some parts of West Africa, where protective efforts are already afoot in Mali and Burkina Faso lauding traditional indigenous adaptations in agriculture, soil care, and land use management. But the impact of these efforts on global pollution is likely to be more limited because their proponents lack resources and influence beyond their domestic spheres.

To conclude, it may be that there are few universals regarding the sources of environmental sentiments. No psychological or socio-structural factors reliably predict public opinion on environmental protection across nations, regions and cultures. Instead, pro-environment attitudes appear to have diverse origins that depend largely on local peculiarities. This leaves us ill-equipped to make confident predictions about the likely success of any future environmental agreements, which must rest on the cooperation of representatives of hundreds of idiosyncratic publics. The most confident prediction we can make is that the values-based frameworks scholars have typically used to explain environmental attitudes, and the politics that result, are of declining utility for analyzing the future of environmentalism. 


\section{Supplementary Materials}

Supplementary materials can be accessed at: http://www.mdpi.com/1996-1073/8/6/4899/s1.

\section{Acknowledgments}

The authors express their appreciation to the World Values Survey Association (www.worldvaluessurvey.org) for the World Values Survey data whose analysis constitutes the core of this paper. We would also like to thank this journal's anonymous reviewers for their comments, which provoked significant improvements in the paper.

\section{Author Contributions}

Both authors contributed substantially to this research article. Stenner conceived and designed the study, analysed the data, and reported and interpreted the results. Nwokora wrote the first draft of the paper, including the literature review. Stenner and Nwokora contributed equally to subsequent expansion and revision of the paper. Both authors have approved the submitted and accepted versions of the manuscript.

\section{Conflicts of Interest}

The authors declare no conflict of interest.

\section{References}

1. Hardin, G. The tragedy of the commons. Science 1968, 162, 1243-1248.

2. Scruggs, L.; Benegal, S. Declining public concern about climate change: Can we blame the great recession? Global Environ. Change 2012, 22, 505-515.

3. Miller, M. Elections, information, and policy responsiveness in autocratic regimes. Comp. Polit. Stud. 2015, 48, 691-727.

4. Ajzen, I. Attitudes, Personality, and Behavior; Open University Press: Milton Keynes, UK, 2003.

5. Diekmann, A.; Preisendörfer, P. Green and greenback: The behavioral effects of environmental attitudes in low-cost and high-cost situations. Ration. Soc. 2003, 15, 441-472.

6. Olofsson, A.; Öhman, S. General beliefs and environmental concern: Transatlantic comparisons. Environ. Behav. 2006, 38, 768-790.

7. Kitschelt, H. Political opportunity structures and political protest: Anti-nuclear movements in four democracies. Br. J. Polit. Sci. 1986, 16, 57-85.

8. Van der Heijden, H.-A. Political opportunity structure and the institutionalization of the environmental movement. Environ. Polit. 1997, 6, 25-50.

9. Van der Heijden, H.-A. Environmental movements, ecological modernisation and political opportunity structures. Environ. Polit. 1999, 8, 199-221.

10. Meguid, B. Competition between unequals: The role of mainstream party strategy in niche party success. Am. Polit. Sci. Rev. 2005, 99, 347-359. 
11. Rohrschneider, R. New party versus old left realignments: Environmental attitudes, party policies, and partisan affiliations in four West European countries. J. Polit. 1993, 55, 682-701.

12. Inglehart, R. The silent revolution in Europe: Intergenerational change in post-industrial societies. Am. Polit. Sci. Rev. 1971, 65, 991-1017.

13. Inglehart, R. The Silent Revolution: Changing Values and Political Styles among Western Publics; Princeton University Press: Princeton, NJ, USA, 1977.

14. Inglehart, R. Modernization and Post-Modernization: Cultural, Economic and Political Change in 43 Societies; Princeton University Press: Princeton, NJ, USA, 1997.

15. Oreg, S.; Katz-Gerro, T. Predicting proenvironmental behavior cross-Nationally: Values, the theory of planned behavior, and value-belief-norm theory. Environ. Behav. 2006, 38, 462-483.

16. Dunlap, R.E.; York, R. The globalization of environmental concern and the limits of the postmaterialist values explanation: Evidence from Four Multinational Surveys. Sociol. Quart. 2008, 49, 529-563.

17. Steel, B.S.; Warner, R.L.; Lovrich, N.P.; Pierce, J.C. The Inglehart-Flanagan debate over postmaterialist values: Some evidence from a Canadian-American case study. Polit. Psychol. 1992, 13, 61-77.

18. Mostafa, M.M. Wealth, post-materialism and consumers' post-environmental intentions: a multilevel analysis across 25 nations. Sustain. Develop. 2011, doi:10.1002/sd.517.

19. Franzen, A. Environmental attitudes in international comparison: An analysis of the ISSP surveys 1993 and 2000. Soc. Sci. Quart. 2003, 84, 297-308.

20 Pralle, S.B. Agenda-setting and climate change. Environ. Polit. 2009, 18, 781-799.

21. Harrison, K.; Sundstrom, L.M. The comparative politics of climate change. Global Environ. Polit. 2007, 7, 1-18.

22. Bean, C.; Papadakis, E. Polarized priorities or flexible alternatives? Dimensionality in Inglehart's materialism-postmaterialism scale. Int. J. Public Opin. Res. 1994, 6, 264-288.

23. Carlisle, J.; Smith, E.R.A.N. Postmaterialism vs. egalitarianism as predictors of energy-related attitudes. Environ. Polit. 2005, 14, 527-540.

24. Duch, R.M.; Taylor, M.A. Postmaterialism and the economic condition. Am. J. Polit. Sci. 1993, 37, 747-779.

25. Davis, D.W.; Davenport, C. Assessing the validity of the postmaterialism index. Am. Polit. Sci. Rev. 1999, 93, 649-664.

26. Davis, D.W.; Dowley, K.M.; Silver, B.D. Postmaterialism in world societies: Is it really a value dimension? Am. J. Polit. Sci. 1999, 43, 935-962.

27. Nisbet, M.C.; Myers, T. Twenty Years of Public Opinion about Global Warming. Public Opin. Quart. 2007, 71, 444-470.

28. Wagner, L.M. Identifying US preferences and a way forward in the ozone, climate and forests regimes. Global Environ. Polit. 2008, 8, 137-142.

29. Brechin, S.R. Objective problems, subjective values, and global environmentalism: evaluating the postmaterialist argument and challenging a new explanation. Soc. Sci. Quart. 1999, 80, 793-809.

30. McGranahan, G.; Balk, D.; Anderson, B. The rising tide: Assessing the risks of climate change and human settlements in low elevation coastal zones. Environ. Urbaniz. 2007, 19, 17-37. 
31. Erda, L.; Wei, X.; Hui, J.; Hu, Y.; Li, Y.; Bai, L.; Xie, L. Climate change impacts on crop yield and quality with CO2 fertilization in China. Philosoph. Trans. Royal Soc. B 2005, 360, 2149-2154.

32. Adeola, F.O. Environmental contamination, public hygiene, and human health concerns in the third world: The case of Nigerian environmentalism. Environ. Behav. 1996, 28, 614-646.

33. Kim, D.-S. Environmentalism in developing countries and the case of a large Korean city. Soc. Sci. Quart. 1999, 80, 810-829.

34. Inglehart, R. Public support for environmental protection: Objective problems and subjective values in 43 Societies. Polit. Sci. Polit. 1995, 28, 57-72.

35. Abramson, P.R.; Inglehart, R. Generational replacement and value change in eight West European societies. Br. J. Polit. Sci. 1992, 22, 183-228.

36. Franzen, A.; Vogl, D. Two decades of measuring environmental attitudes: A comparative analysis of 33 countries. Global Environ. Change 2013, 23, 1001-1008.

37. Ivanova, G.; Tranter, B. Paying for environmental protection in a cross-national perspective. Aus. J. Polit. Sci. 2008, 43, 169-188.

38. Rohrschneider, R. Citizens' attitudes toward environmental issues: Selfish or selfless? Comp. Polit. Stud. 1988, 21, 347-367.

39. Franzen, A.; Meyer, R. Environmental attitudes in cross-national perspective: A multilevel analysis of the ISSP 1993 and 2000. Eur. Sociol. Rev. 2010, 26, 219-234.

40. Gelissen, J. Explaining popular support for environmental protection: A multilevel analysis of 50 nations. Environ. Behav. 2007, 39, 392-415.

41. Knight, K.W.; Messer, B.L. Environmental concern in cross-national perspective: The effects of affluence, environmental degradation, and world society. Soc. Sci. Quart. 2012, 93, 521-537.

42. Norris, P. The globalization of comparative public opinion research. In The Sage Handbook of Comparative Politics; Robinson, N., Landman, T., Eds.; London, UK, 2009; pp. 522-540.

43. Huntington, S.P. The clash of civilizations? Foreign Aff. 1992, 72, $22-49$.

44. Pemstein, D.; Meserve, S.A.; Melton, J. Democratic compromise: A latent variable analysis of ten measures of regime type. Polit. Anal. 2010, 18, 426-449.

45. Heston, A.; Summers, R.; Aten, B. Penn World Table Version 7.0 (PWT 7.0) 2011. Center for International Comparisons of Production, Income, and Prices, University of Pennsylvania. Available online: http://pwt.econ.upenn.edu/php_site/pwt_index.php (accessed on 1 July 2011).

46. Evans, G.; Heath, A. The measurement of Left-Right and libertarian-authoritarian values in the British electorate. Qual. Quant. 1995, 29, 191-206.

47. Stenner, K. Three kinds of "conservatism". Psychol. Inq. 2009, 20, 142-159.

48. Altemeyer, R. The Authoritarian Specter; Harvard University Press: Cambridge, MA, USA, 1996.

49. Feldman, S.; Stenner, K. Perceived threat and authoritarianism. Polit. Psychol. 1997, 18, 741-770.

50. Hetherington, M.J.; Weiler, J.D. Authoritarianism and Polarization in American Politics; Cambridge University Press: New York, NY, USA, 2009.

51. Stenner, K. The Authoritarian Dynamic. Cambridge University Press: New York, NY, USA, 2005.

52. Levi, M.; Stoker, L. Political trust and trustworthiness. Ann. Rev. Polit. Sci. 2000, 3, 475-507.

53. Lubell, M. Familiarity breeds trust: collective action in a policy domain. J. Polit. 2007, 69, 237-250.

54. McCright, A.M.; Dunlap, R.E. Anti-reflexivity: The American conservative movement's success in undermining climate science and policy. Theor. Cult. Soc. 2010, 27, 100-133. 
55. Downs, A. Up and down with ecology-The 'issue-attention' cycle. Public Interest 1972, 28, 38-50.

56. Page, B.I.; Shapiro, Y. Effects of public opinion on policy. Am. Polit. Sci. Rev. 1983, 77, 175-190.

57. Kelemen, R.D. Globalizing European Union environmental policy. J. Eur. Public Pol. 2010, 17, 335-349.

58. Schreurs, M.A.; Tiberghien, Y. Multi-level reinforcement: Explaining European Union leadership in climate change mitigation. Global Environ. Polit. 2007, 7, 19-46.

59. Baer, H.; Singer, M. Global Warming and the Political Ecology of Health: Emerging Crises and Systematic Solutions; Left Coast Press: Walnut Creek, CA, USA, 2009.

60. Koehn, P.H. Underneath Kyoto: Emerging subnational government initiatives and incipient Issue-Bundling opportunities in China and the United States. Global Environ. Polit. 2008, 8, 53-77.

(C) 2015 by the authors; licensee MDPI, Basel, Switzerland. This article is an open access article distributed under the terms and conditions of the Creative Commons Attribution license (http://creativecommons.org/licenses/by/4.0/). 